\title{
TRES MIRADES SOBRE LA VALÈNGIA DE POSTGUERRA: TRANVÍA $A$ LA MALVAROSA, EL CRIMEN DEL CINE ORIENTE I GRÀCIES PER LA PROPINA
}

\author{
Joaquim Espinós Felipe
}

Universitat d'Alacant

Entre els anys 1996 i 1997 van coincidir en la cartellera espanyola tres títols que tenien la València franquista o tardofranquista com a marc referencial. Es tracta de Tranvía a la Malvarosa (1996), de José Luís García Sánchez; El crimen del cine Oriente (1997), de Pedro Costa, i Gràcies per la propina, (1997) de Francesc Bellmunt. Aquesta coincidència resulta sorprenent, donada l'escassesa de representacions cinematogràfiques d'aquesta època i lloc, i creiem que bé es mereix un comentari. Abans d'ocupar-nos de cada obra concreta, caldria esmentar alguns aspectes que relacionen entre si els tres films. En primer lloc, ressaltar que els podríem situar, en major o menor mesura, dins del corrent cinematogràfic que des de la transició democràtica fins als nostres dies pretén una recuperació de la memòria sentimental de la vida davall el franquisme, i que ha tingut les ciutats de Madrid, en primer terme, i Barcelona, secundàriament, com a referents predilectes. En segon Iloc, tots ells es basen en textos literaris, les novel·les homònimes de Manuel Vicent, Javier Tomeo i Ferran Torrent. Des d'una perspectiva temporal, Tranvía a la Malvarosa i El crimen del cine Oriente presenten una major proximitat: ambdós se situen en la dècada de 1950. Gràcies per la propina, per la seua banda, discorre entre els anys seixanta i inicis dels setanta. Des d'un punt de vista genèric, mentre que El crimen del cine Oriente s'adscriu a la crònica negra, Tranvía a la Malvarosa i Gràcies per la propina són relats d'iniciació. En aquest sentit, la seua inspiració en les novel·les autobiogràfiques de Manuel Vicent i Ferran Torrent resulta determinant.

\section{TRANVÍA A LA MALVAROSA}

Tal com acabem de ressenyar, I'adaptación de García Sánchez, fidel en línies generals a la novel.la de Manuel Vicent, segueix l'estructura clàssica d'una història de formació, on el viatge d'anada i tornada del poble — el fictici Torre del Mar en el film, Vilavella en la novel.la_ a València marca l'evolució del narrador autodiegètic. S'inicia la pel-lícula amb l'arribada de Miguel al poble, procedent de l'internat religiós. En aquesta primera part la seua iniciació 
sexual de la mà del Bola, mestre en les arts hedonistes, centrarà les peripècies argumentals. Una iniciació que l'ànsia de puresa de Miguel, fruit d'una fèrria educació religiosa, dilatarà fins molt més tard, contraposant-la a la recerca de l'amor romàntic representat per Marisa, una angelical adolescent que estiueja en el poble. Aquesta dualitat sexe-amor recorrerà tota la pel-lícula. La segona part és la que transcorre a la ciutat de València. Allí Miguel entrarà en contacte amb el món universitari i intel·lectual, determinant en la seua formació, perseguirà la fantasmal Marisa, objecte del desig més somiat que real, i coneixerà per fi el sexe, de la mà d'una estranya dona que creu veure en ell la reencarnació d'un nuvi mort. De manera paral·lela, descobrirà la vocació d'escriptor, que una vegada perduda la fe religiosa, donarà nou sentit a la seua vida. La tornada al poble durant les vacances de Pasqua estarà marcada per la mort del Bola en un accident de moto, que com subratlla la veu en off, suposarà la fi de la seua adolescència. De nou a València, coneixerà l'amor amb Juliette, una jove francesa que una vegada més encarna la llibertat moral.

L'ordre del text fílmic s'estructura de manera més lineal que el text literari, molt més pròxim a la sinuosa temporalitat del record. L'adaptació cinematogràfica basa la seua coherència en paràmetres geogràfics abans que temporals. A l'oposició poble-ciutat cal afegir, ja en el marc urbà, la de ciutat-platja. És en el tramvia que dóna títol a l'obra on, tot just arribar a València, veurà l'estimada Marisa. A partir de llavors, els omnipresents tramvies adquiriran un creixent sentit simbòlic, lligat al món del somni, del desig impossible, que conflueix amb el simbolisme marí del seu destí final. El caràcter oníric del tramvia —inevitable I'associació amb el tramvia anomenat desig de Tenessee Williams- s'explicita en la seqüència en què Miguel ix de la presó després d'haver assistit a l'execució del Semo, condemnat per la violació i assassinat d'una xica. L'execució provoca en el jove protagonista una fonda commoció. És llavors quan de nou emergeix el tramvia, amb una Marisa més espectral que mai perdent-se en la boira, en la nit, en el no-res. La seqüència següent, la del naixement de la seua vocació d'escriptor, reforça la transcendència d'aquesta visió nocturna. Sobre la imatge del jove Miguel assegut en un escriptori, que deixa de banda els apunts per a escriure la història del Semo, la veu en off del Miguel adult ens relata: "Su imagen imposible empezó a ser sustituida por un deseo de reordenar el mundo por medio de la literatura". La pel.lícula, a més, accentua el vessant melodramàtic de la història: en el llibre no és la consciència de la impossibilitat de l'amor, sinó la pèrdua de la fe en Déu, el principal catalitzador de la vocació escriptora.

El mar, com ja hem observat, juga un important paper en el simbolisme espacial de Tranvia a la Malvarosa. A més de la seua vinculació amb l'ideal amorós, representa un contrapunt de llibertat i hedonisme enfront de la repressió urbana. Els moments en què els espais marins apareixen, resulten, per contrast, altament significatius: després de l'arribada de Miguel a una València presa per la policia amb motiu de la visita del caudillo, després de la seua frustració en comprovar que la xica que l'esperava a l'eixida de missa no és Marisa, després d'assistir a uns exercicis espirituals esperpèntics, de les advertències antisensuals del catedràtic de dret o de la mort del Bola, i al final de la pel-lícula, lligat al descobriment de l'amor amb Juliette. Un descobriment que s'identificarà amb el de la vocació escriptora. Sobre una panoràmica marina, s'escolta una vegada més la veu en off: "El mar, sería el fin del viaje. Las sensaciones, perfumes, sonidos i sabores placenteros que inundaban la crueldad del garrote vil, en medio de los cuales el mar y Juliette ya eran la misma sustancia. Este placer de los sentidos, también tendría que expresarlo con algunas palabras escritas". 
Si abandonem el sentit simbòlic de l'espai —la poètica de l'espai, en termes bachelardians - i ens centrem en el pròpiament referencial, observem que la mirada de García Sánchez oscillla entre la codificació realista i la costumista. En ambdós casos, el director, com l'escriptor, tendirà a una pintura més aviat amable per nostàlgica de la realitat valenciana de postguera. El context històric es dibuixa fragmentàriament, sense arribar mai a superar la seua condició de mer decorat per al desenvolupament de l'educació sentimental del protagonista. Així, tan bon punt arriba a València, Miguel és testimoni del control policial a què es veu sotmesa la ciutat amb motiu de la visita de Franco per a entrevistar-se amb el comandament de la VII flota nord-americana. Aquest acte té un gran sentit històric, en tant que s'emmarca en la fi de l'etapa autàrquica del règim, quan en els anys cinquanta comença a ser reconegut per les institucions internacionals. Després del control policial, la visita del generalísimo ens és mostrada en els seus aspectes més festius: I'ornamentació dels carrers, els pastissos que representen la seua efígie, la desfilada del seu seguici... No resulta gens estrany que siga així, atés que la realitat apareix sempre filtrada pels ulls de Miguel, que nouvingut a la ciutat i amb escassa o nul-la consciència política — la pròpia d'un senyoret rural—, assisteix fascinat a l'espectacle urbà. Un espectacle amb tints còmics que deriven perillosament cap al pintoresc. Així, les seqüències dels capellans aprenent a escriure a màquina en un soterrani, d'aires fellinians; la del botiguer intentant ensenyar el seu lloro a dir «visca el Valencia» o la del baret amb molinets de colors, situades totes abans de l'arribada del jove al col.legi major, prefiguren ja el tractament que de la realitat urbana farà l'adaptació de García Sánchez, molt fidel en aquest punt a la novel·la de Vicent. Un tractament superficial, tòpic, que en les seqüències més purament descriptives mostra escenes de la vida popular del centre històric de València - Llotja, Mercat, plaça Redóna- i que quan es tracta de caracteritzar els personatges episòdics — cas de la venedora de fruites del mercat, de l'arribada del capità general al local de la platja o del predicador interpretat per Juan Luis Galiardo- deriva decididament cap a l'estètica fallera amb regustos berlanguians.

Respecte als espais interiors, relacionats amb l'educació del protagonista -el col·legi major, la universitat o el despatx del confessor- tenen en comú el fet d'exercir d'agents repressors de la incipient sensualitat i la curiositat intel-lectual, encara que en el cas de la universitat, li proporcionen també l'estímul necessari per a buscar un camí alternatiu. Els guionistes aporten, per a aqueix fi, un personatge inexistent en la novel.la, el del professor adjunt compromés amb la resistència antifranquista, que farà de guia intel/lectual de Miguel en el seu procés de conscienciació: li regalarà els llibres dels nous mestres ideològics -Camus, Sastre...-, el posarà en contacte amb les tertúlies de la intel-lectualitat valenciana —Fuster, Ventura, lborra-i, sobretot, li proporcionarà l'accés a l'execució del Semo, fet determinant en la seua pèrdua de la innocència. Una execució que no deixa de tindre, de nou, un to grotesc: convencen el reu per a confessar-se amb la promesa d'un més enllà on podrà menjar paella tots els dies.

No hem d'oblidar, en el tractament fílmic d'aquest procés d'aprenentatge, la importància de les llibreries de vell, on Miguel acudeix a proveir-se dels títols prohibits: L'immoralista, Els grans cementeris davall la lluna o Per qui sonen les campanes. Especial menció mereixen, també, els espais relacionats amb la iniciació sexual del personatge, verdadera línia de força de la narració i, en general, de tota novel·la d'aprenentatge. Ja hem citat la fallida visita al prostíbul de Castelló del virginal i místic Miguel. Una vegada a València, la seua aproximació al sexe corre paral-lela a l' allunyament de la fe religiosa. Les principals parades d'aquest 
recorregut per una València que és qualificada pel seu confessor de nova Babilònia serien el local on es reuneixen els tractants de bestiar, que animen amb entusiasme les femelles que gosen passar per allí; l'espectacle de varietés on presencia bocabadat el top less de l'artista davant de la indignació dels capellans, la visita al puticlub de València amb el Bola, —on per cert es parlarà del crim del cine Oriente- i, sobretot, la pertorbadora relació amb la Xina, amb qui finalment coneixerà les delícies del sexe, delícies que continuarà amb Juliette en la casa abandonada de Blasco lbáñez en la Malvarosa: la pulsió sexual i la d'escriptura hi resten feliçment unides.

\section{GRÀCIES PER LA PROPINA}

Amb Gràcies per la propina Ferran Torrent va donar un gir intimista a la seua producció, que fins llavors i també de manera predominant en la seua obra posterior, s'havia situat en l'òrbita del gènere policíac. En l'obra que ens ocupa, adaptada fidelment per Francesc Bellmunt, la vida del seu protagonista i narrador, Ferran Torres, transcorre també entre el poble —Benicorlí_ i la ciutat —València_, amb especial preferència pel primer. La pel-lícula comença amb la reunió dels germans Torres -Ferran i Pepín- en la casa familiar, escenari de les seues principals vivències, just la nit abans de la seua demolició. La veu en off ens introduïx llavors en el llarg flash back que constitueix la quasi totalitat del film.

L'etapa infantil s'ubica en el poble, alternant el to de comèdia irreverent —la magnífica arrancada masturbatòria del protagonista abans de complir la primera comunió, les ensenyances eròtiques de l'amic major — amb el to dramàtic —el suïcidi de la mare—, que hi resta diluït. Aquesta alternança es mantindrà al llarg de tota l'obra. A resultes de la mort de sa mare, els dos xiquets viuran a casa de l'avi i els dos oncles, que conformen una família atípi$\mathrm{ca}$, amb un sistema de valors totalment oposat als del franquisme. Especialment important resulta la figura de l'oncle Tomàs, que iniciarà els xiquets en els més rellevants aspectes de l'existència: el treball i el sexe. I el que és més important, els ensenyarà a viure com a esperits lliures. El personatge de Tomàs, per cert, està interpretat per Santiago Ramos, que a Tranvía a la Malvarosa feia de narrador. Heus ací un nou vincle entre els dos films.

Aqueix aprenentatge de la llibertat comença en el col-legi dels jesuïtes, del qual seran expulsats, i continua en els carrers de la València dels anys seixanta i inicis dels setanta. Una València que recorreran de la mà de Tomàs, i que en oposició a Benicorlí, apareix com un espai de diversió. Mentre que en el poble la repressió franquista es mostra encara amb tota cruesa, concentrada en les figures del guàrdia civil i el capellà, a València els joves descobriran els plaers de la nit, en el més ampli sentit de la paraula. "Sovint a la nit —remarcarà la veu narradora- ens traslladàvem a València, on en aquell temps la vida nocturna tènia una dimensió popular». El barri xinés, a la descripció física i conceptual del qual se li dediquen en la novel·la unes acolorides pàgines que no tenen el seu reflex en el film, serà l'epicentre d'aquesta vida nocturna. En les dites pàgines es destaca com per a molts habitants dels pobles limítrofs, anar a València era sinònim d'anar al Chino, així com el caràcter d'impunitat moral —en matèria eròtica-que hi regnava. En la pel-lícula, tota aquesta animació popular desapareix, ja que el debut eròtic dels adolescents - la propina del títol— se situa en l'asèptic interior d'un pis.

La descripció de la bulliciosa nit valenciana del tardofranquisme és una de les parts més divertides de la pel-lícula. Acudiran al cine, on coneixeran algunes de les núvies de Tomás; als combats de catch, que enfrontaven a personatges mítics com El Santo i Tupac Amaru, o a la 
boxa, en locals clandestins de la perifèria, en els quals Ferrán iniciarà una tímida carrera que acabarà amb una sobirana palissa. Especial importància tenen els espectacles de variétés. Oncle i nebots frecuentavan el Russafa, on la vedette Rosita Amores, que també apareix a I'obra de García Sánchez, exercia de reina absoluta. Ací també assistim a un improvisat top less, que farà les delícies del respectable, lliures de la coherció dels capellans. L'escena és subratllada per la veu en off: «Tots els decrets del franquisme sobre la moral i els bons costums quedaren abolits en aquell escenari». El sexe, al llarg de tota la pel-lícula, és vist com una força transgressora en el context repressiu de les acaballes del franquisme.

Un altre espai lúdic i popular serà El Boquerón, el bar a què acudiran a la vesprada, al final del treball. Un bar regentat per Flora, una puta retirada més coneguda per «la valenciana de cementos» per la contundència dels seus pits. El Boquerón és propietat de El Fino, gitano elegant, com el seu nom indica, que no dubtarà a partir-li elegantment la cara a Flora quan s'assabente del seu afer amb Pepín.

La predilecció de l'adaptació fímica de Gràcies per la propina per la València popular s'explicita també en els paisatges urbans triats com a exteriors: quan Ferran ha de vigilar l'oncle Ramonet per a esbrinar amb qui es cita, la pensió a què acudeix està en la Plaça Redona, un dels llocs més pintorescos del seu centre històric. També a Tranvía a la Malvarosa sucumbien al seu encant.

Per a acabar, voldríem comentar el tractament que s'hi fa dels tramvies. Ací no jugaran un paper simbòlic com el de la Malvarosa en la pel-lícula homònima, seran, senzillament, l'escenari dels ardorosos fregaments dels germans protagonistes amb les temptadores col·legiales. I amb alguna senyora airada que acabarà amb el seu joc eròtic a galtades.

\section{EL CRIMEN DEL CINE ORIENTE}

De les tres pel-lícules que estem ressenyant, El crimen del cine Oriente és la que menys metratge dedica a la ciutat de València, a pesar de transcórrer-hi quasi en la seua totalitat. Això és degut a la seua ambientació preferent en l'espai claustrofóbic del cine Oriente, amb escasses però significatives concessions als espais oberts.

La pel-lícula s'inicia amb el personatge d'Anabel Alonso en la platja, en un dia plujós, amb una maleta. És la viva imatge de la desolació. Després la veiem caminar per uns carrers humils fins a arribar a una plaça, detindre's davant del cine i introduir-se a veure una pel-lícula. Es quedarà dormida, i aquest serà l'inici de la seua morbosa relació amb l'encarregat del cine. Encara que no s'explicita el nom de la ciutat, l'ambientación valenciana s'evidencia en els noms dels personatges —Amparito, Riquelme, Sendra, Asensi..._ i dels llocs —Bar Manises-. De fet, la novel.la manté encara una indefinició espacial major, amb concises referències al mar o al puticlub on treballava la protagonista-narradora - Canyar- Cal consignar que la pel-lícula es basa en un fet real succeït en la València dels cinquanta, encara que la majoria dels espectadors ja no en tinguen constància. La trama policíaca serveix a Pedro Costa per a descriure fredament la misèria moral de la societat espanyola del franquisme. Els dos protagonistes la representen a la perfecció: ell és un fracassat, un pobre diable, borratxo i petulant; ella una jove humil, víctima des de petita de l'assetjament dels homes. L'encarregat del cine és l'última baula en la cadena d'humiliacions que ha hagut de suportar, encara que en la pel-lícula, en el guió de la qual col-labora el mateix Tomeo, se suavitza un poc la seua trajectòria, tot canviant la condició de prostituta pel de criada. La mateixa direcció edulcorant 
segueixen altres canvis introduïts, com el tractament dels personatges secundaris -la taquillera, I'acomodador o el projeccionista-, que afigen un contrapunt costumista, humanizador, a la sordidesa de la trama principal; o el contrast glamourós - a l'estil Cinema paradiso- de les pel-lícules que s'hi projecten, que ofereixen, que adquireix tons tremendistes en la seqüència en què ella està esquarterant i afaitant el cadàver darrere de la pantalla mentre s'hi contempla una idíllica escena d'amor.

Al llarg del film, de manera complementària als interiors del cine, se'ns mostren alguns ambients populars predominantment lluminosos: el bar Manises, els billars, la plaça de bous o el barri xinés. També ací un dels pocs moments feliços se situa en la platja, amb la paella que els empleats del cine fan per a celebrar la jubilació del projeccionista. Per contra, les eixides nocturnes de l'homicida per a desfer-se dels braços i les cames del seu amant ens mostren una València ombrívola i amenaçadora, dins de la tradició del gènere negre.

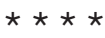

Després d'aquest ràpid recorregut per tres pel-lícules que tenen com referent la València dels anys cinquanta i seixanta, hem pogut observar que la imatge que se'ns ofereix oscilla entre la idealització nostàlgica de Tranvía a la Malvarosa i Gràcies per la propina, i la sordidesa d'El crimen del cine Oriente, que presenta, ja des de la seua adscripció genèrica policíaca, una major voluntat de denúncia. En conjunt, en les tres obres, amb els matisos corresponents, predomina la idea que la vida quotidiana en la ciutat aconseguia sobreposar-se a l'opressiu ambient de la Dictadura. Entre els carrers de la València cinematogràfica bull una vida que desborda en els seus bars, cines, puticlubs, col-legis, mercats... Fins i tot en els seus crims.

\section{BIBLIOGRAFÍA}

TOMEO, Javier (1995), El crim del cine Orient, Barcelona, Plaça \& Janés.

TORRENT, Ferran (1995), Gràcies per la propina, Alzira, Bromera.

VICENT, Manuel (1994), Tranvía a la Malvarosa, Madrid, Alfaguara. 